\title{
Influence of the tropics on the climate of the South Atlantic
}

\author{
Semyon A. Grodsky ${ }^{1}$ and James A. Carton ${ }^{1}$ \\ Received 11 November 2005; revised 17 February 2006; accepted 20 February 2006; published 31 March 2006.
}

[1] The climate of the tropical Atlantic is shown to undergo slow basinwide changes with time-scales of five years that include changes in surface winds, SST, and sea level. Further south in the Agulhas eddy corridor $35^{\circ} \mathrm{S}-$ $25^{\circ} \mathrm{S}$ there are sea level fluctuations (superimposed on the dominant mesoscale eddies) on a similar timescale with amplitudes of $10 \mathrm{~cm}$ and with westward phase propagation of $4 \mathrm{~cm} \mathrm{~s}^{-1}$, giving rise to phase variations between the western and eastern sides of the basin. In the eastern basin sea level anomalies are accompanied by $0.5^{\circ} \mathrm{C}$ SST variations, while in the west the relationship is more complex. Here we explore the possibility that these subtropical sea level fluctuations are produced by the poleward propagation of the tropical sea level anomalies. Citation: Grodsky, S. A., and J. A. Carton (2006), Influence of the tropics on the climate of the South Atlantic, Geophys. Res. Lett., 33, L06719, doi:10.1029/2005GL025153.

\section{Introduction}

[2] Recent studies have identified fluctuations in the climate of the South Atlantic sector including the strength and position of the South subtropical high pressure system and SST. These studies have focused on the role of local airsea interactions [Venegas et al., 1997; Sterl and Hazeleger, 2003], remote influences from the Pacific, particularly ENSO [Venegas et al., 1997; Campos et al., 1999; Colberg et al., 2004], and oceanic exchanges with the Indian Ocean [e.g., Gordon et al., 1992; Matano and Beier, 2003]. Here we use an extended observational record to explore a fourth source of climate variability in which climate signals produced in the tropical Atlantic influences the SST and thus climate of the south Atlantic.

[3] The anticyclonic surface winds of the South Atlantic are controlled by the position and intensity of the south subtropical high pressure zone, both of which exhibit rich spectra of interannual to decadal variations [Venegas et al., 1997; Feistel et al., 2003]. The resulting southern subtropical oceanic gyre is located between the northeastward South Equatorial Current to the north and the westward South Atlantic Current in the south [Peterson and Stramma, 1991]. Associated with this anticyclonic gyre is a sea level maximum, while on the southern edge of the gyre between $35^{\circ} \mathrm{S}-25^{\circ} \mathrm{S}$ is a zonal band of high eddy variability known as the Agulhas eddy corridor (AEC) [Garzoli and Gordon, 1996].

[4] The interannual and decadal variability of South Atlantic SST has been linked to fluctuations of the strength

\footnotetext{
${ }^{1}$ Department of Atmospheric and Oceanic Science, University of Maryland, College Park, Maryland, USA.

Copyright 2006 by the American Geophysical Union. 0094-8276/06/2005GL025153\$05.00
}

and position of the south subtropical high in sea level pressure [e.g., Venegas et al., 1997; Wainer and Venegas, 2002]. Its variability affects the strength of the southeasterly trade winds to the north of the high as well as the strength of the westerly winds to the south of the high and also affects the intensity of the oceanic currents along the coast of Argentina that, in turn, impact SST in the subtropical western South Atlantic through anomalous advection.

[5] The response of the atmospheric circulation to the SST anomalies in the South Atlantic has been examined by Robertson et al. [2003] and Haarsma et al. [2003] who have shown that the dipole pattern of SST in the South Atlantic produces a deep baroclinic response in the atmosphere over the warm equatorward half of the dipole. This response in turn results in a southward displacement of the ITCZ, hence a northerly cross equatorial anomalous flow and weakening of the southeasterly trade winds over the equator.

[6] In contrast, along the equator variability is introduced through local and remote air-sea interaction, both of which may cause the trade winds along the equator to relax, allowing an eastward surge of warm thermocline water into the normally cool eastern Gulf of Guinea [Servain et al., 1982; Carton et al., 1996]. This excess warm water may propagate poleward along southwestern African shelf, suppressing the seasonal cool upwelling along this coast [Hirst and Hastenrath, 1983; Florenchie et al., 2003; Schouten et al., 2005].

[7] As indicated above, three hypotheses have been put forward to explain the existence of interannual variations in the climate of the South Atlantic: local coupled atmosphereocean interaction, atmospheric teleconnections from the tropical Pacific, and oceanic transport from the Indian Ocean. The third mechanism was articulated by Witter and Gordon [1999] based on examination of a short 4-year long altimeter sea level record. In this paper we revisit the causes of climate variability in the South Atlantic, extending the analysis of Witter and Gordon using a longer 13-year sea level record (October, 1992 through June, 2005) together with corresponding SST and wind observations. In this still too limited record we find evidence in the subtropical South Atlantic of tropical Atlantic influences, particularly in the eastern basin.

\section{Data and Methods}

[8] This study relies heavily on a number of observational data sets, including sea level, SST, and winds. We obtained a merged altimeter-based monthly sea level from the Archiving, Validation and Interpretation of Satellite Oceanographic data (AVISO) web site. AVISO sea level is the result of a merged reprocessing of six altimeter data sets: TOPEX/Poseidon, Jason and ERS-1/2, ENVISAT, and is computed on a $1 / 3^{\circ} \times 1 / 3^{\circ}$ grid [Ducet et al., 2000]. 

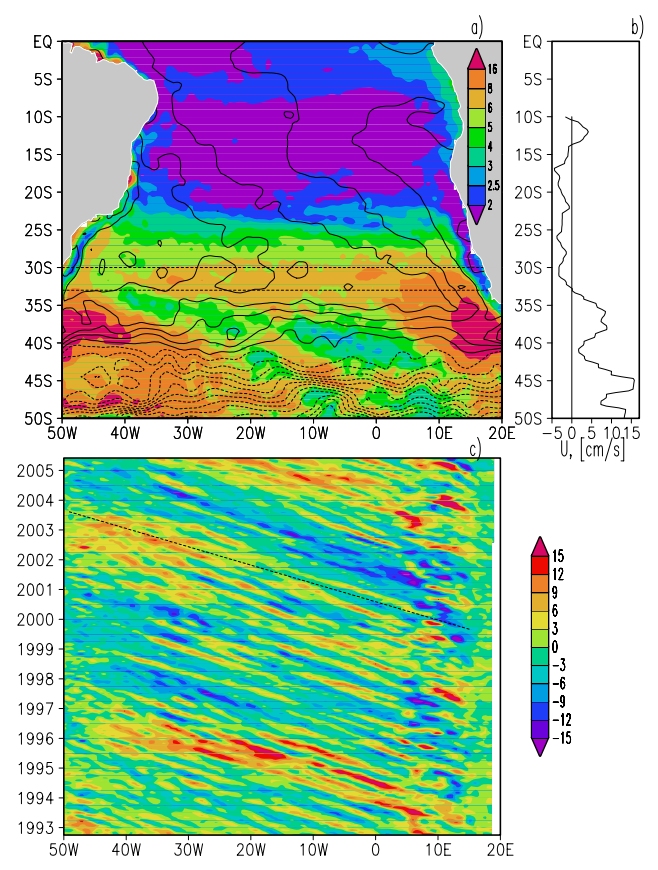

Figure 1. (a) Standard deviation of the sea level (shading) and the mean absolute dynamic topography (contours, $\mathrm{CI}=$ $10 \mathrm{~cm}$, contours below $140 \mathrm{~cm}$ are shown as dashed lines). (b) Mean zonal geostrophic current averaged $10^{\circ} \mathrm{W}-10^{\circ} \mathrm{E}$. (c) Sea level anomalies averaged within the $33^{\circ} \mathrm{S}-30^{\circ} \mathrm{S}$ band shown in Figure 1a. Slope of the dotted line corresponds to an eddy speed of $5.2 \mathrm{~cm} \mathrm{~s}^{-1}$. All data are in $\mathrm{cm}$.

Mean absolute dynamic topography is also provided by AVISO based on a Geoid calculated with the EGM96 geopotential model (see p.32 at http://www.jason. oceanobs.com/documents/donnees/tools/handbook jason.pdf).

[9] The SST data set is based on a combination of in situ observations and satellite infrared radiances [Reynolds and Smith, 1994] and is available on a $1^{\circ} \times 1^{\circ}$ grid for our full 13 -year period of interest. A continuous wind record is provided by two satellite-based surface wind analyses. The Special Sensor Microwave Imager (SSM/I) wind velocity of Atlas et al. [1996] is available beginning 1987 on a $1^{\circ} \times$ $1^{\circ} \times 1$-month grid. A second product, the QuikSCAT wind velocity of Graf et al. [1998] is available on a $0.5^{\circ} \times 0.5^{\circ} \times$ 12 hour grid from the Seawinds web site at NASA/JPL beginning July 1999.

[10] All data sets are converted to monthly averaged anomalies with respect to the 13-year monthly climatology. In order to identify connections between oceanic and atmospheric variables we decompose several variables using a simple Empirical Orthogonal Function decomposition (without rotation). Correspondence among variables is examined by determining the projection of the principal component time series.

\section{Results}

[11] Sea level variability in the South Atlantic is concentrated in two regions, the Agulhas retroflection area in the east and the Brazil-Malvinas confluence area in the west (Figure 1a). Sea level variability is also seen to increase above $5 \mathrm{~cm}$ RMS in the AEC, roughly between $35^{\circ} \mathrm{S}$ and $25^{\circ} \mathrm{S}$, which follows the northern flank of the South Atlantic Current (SAC). Many of the AEC eddies originate in the Agulhas retroflection area between $40^{\circ} \mathrm{S}-35^{\circ} \mathrm{S}$, initially translating northwestward, and then crossing into the eastward flowing SAC (Figure 1b).

[12] As the eddies move further north the mean zonal current slows. By $35^{\circ} \mathrm{S}$ the SAC speed is reduced to the magnitude of the westward eddy propagation velocity $(5 \mathrm{~cm} / \mathrm{s}$, Figure $1 \mathrm{c})$ and the eddies start moving westward along the northern flank of the SAC into the subtropical gyre. Superimposed on the intraseasonal eddy variability of the AEC sea level also reveals the presence of slow 45 year time-scale fluctuations with $10 \mathrm{~cm}$ amplitude that propagate westward (Figure 1c). Indeed, the speed of propagation is sufficiently slow that sea level varies out of phase between the eastern and western side of the basin implying slow variations in basin-average geostrophic meridional velocity of $0.25 \mathrm{~cm} \mathrm{~s}^{-1}$.

[13] Different hypotheses can be put forward to explain the interannual sea level fluctuations. They could, for example, result from interannual variations in the number of cyclonic versus anticyclonic eddies. However a cursory examination shows homogeneous statistics. They could also reflect the presence of local wind-generated Rossby Waves. However we find only a weak correlation $\left(r^{2}<0.3\right)$ between interannual sea level and local Ekman pumping. Finally, they could be forced remotely. In order to explore this last possibility we begin by decomposing the 13-year sea level anomaly record into Empirical Orthogonal Functions (EOFs).

[14] A noticeable feature of the leading sea level EOF is a pattern of variation in the eastern equatorial Atlantic and the eastern subtropics, which varies coherently with tropical winds and SST (Figure 2). Previous studies of equatorial seasonal variability have shown the accumulation of excess thermocline water in the eastern Gulf of Guinea and

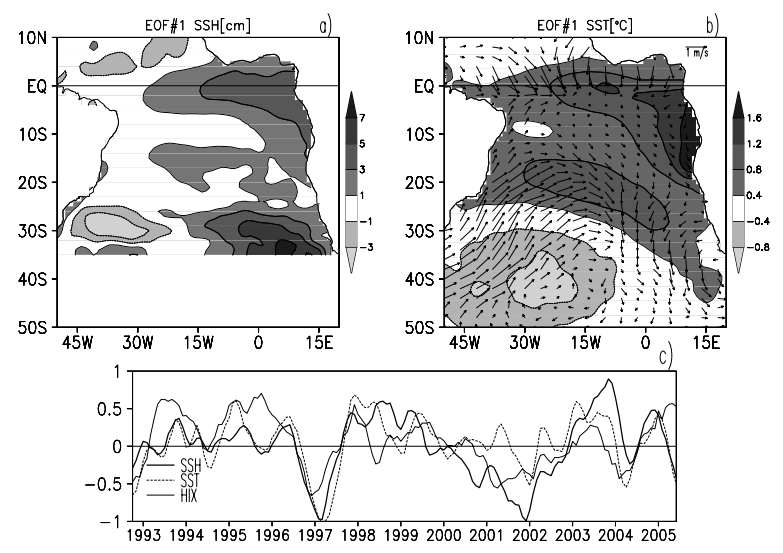

Figure 2. (a and b) Spatial pattern and (c) time series of the leading EOF of the sea level (SSH, 27\% of variance) and SST (24\%). Regression of winds on the sea level EOF time series is overlain in Figure 2b. Running one year smoothed St. Helena climatic index (HIX) is shown in Figure 2c. HIX is the time series of the leading EOF of pressure, temperature, and precipitation at the St. Helena weather station record. An inverse value of the HIX is shown for comparison. 

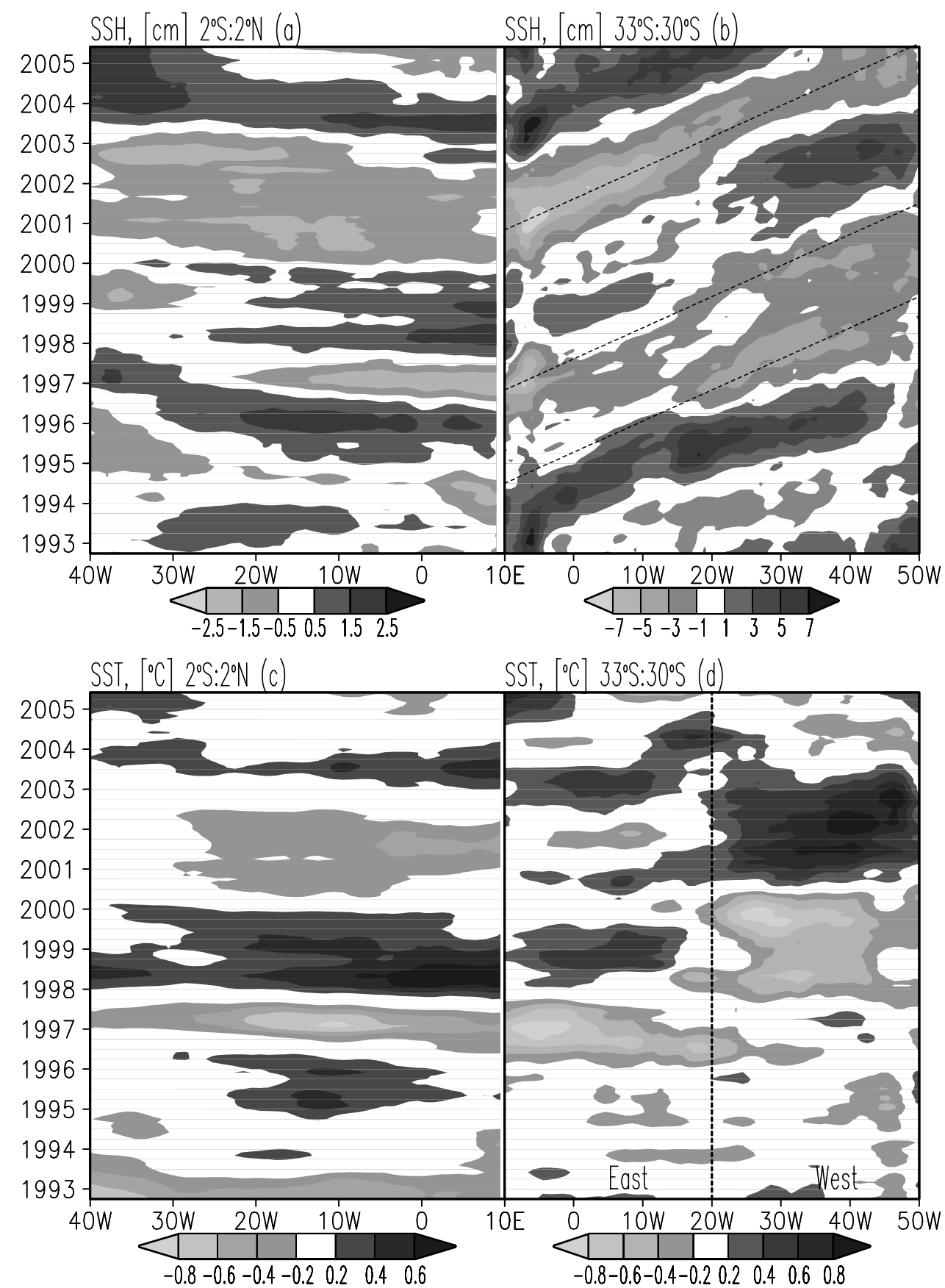

Figure 3. ( $a$ and b) Annual running mean sea level and ( $c$ and d) SST anomalies along the equator (Figures $3 a$ and 3c) and along the Agulhas eddy corridor (Figures $3 \mathrm{~b}$ and $3 \mathrm{~d}$ ). Slope lines in Figure $3 \mathrm{~b}$ correspond to a $4 \mathrm{~cm} \mathrm{~s}^{-1}$ westward velocity.

consequent rise of sea level during some years. Studies of the relationship between sea level and stratification in the tropics suggest that a $1-2 \mathrm{~cm}$ rise in sea level reflects a $2-$ $4 \mathrm{~m}$ deepening of the thermocline throughout a region of some $3 \times 10^{6} \mathrm{~km}^{2}$ [Carton et al., 1996]. This seasonal excess thermocline water propagates poleward along the coast of Africa, eventually detaching from the coast and propagating westward [e.g., Hirst and Hastenrath, 1983; Schouten et al., 2005]. Because of the rapid speed of coastal waves, poleward propagation of low frequency anomalies appears as coherent alongshore variations. As in the case of seasonal anomalies, the appearance of coherent anomalies in Figure 2a is attributed to poleward propagation. This correspondence is particularly evident after 1996 (Figures 3a and $3 \mathrm{~b}$ ). By $30^{\circ} \mathrm{S}$ westward propagation of sea level variations becomes noticeable with $10 \mathrm{~cm}$ amplitudes and a slow westward speed of $4 \mathrm{~cm} / \mathrm{s}$. The westward phase speed is faster than the speed of long first baroclinic Rossby Waves (assuming a gravity wave speed of $2.5 \mathrm{~m} / \mathrm{s}$ ) which in part may be explained by the increase in speed due to the presence of vertical shear [Killworth et al., 1997].

[15] We next consider the implications of this tropicalextratropical connection for the climate of the South Atlantic through the relationship between interannual sea level and SST. Along the equator and in the Gulf of Guinea $0.5^{\circ} \mathrm{C}$ fluctuations in SST vary in phase with sea level (and thus 
stratification) as shown in Figure 2, a result of the important role that the process of entrainment plays in regulating the heat budget of the mixed layer. This inphase relationship between SST and sea level extends into the southeastern subtropics (Figure 3) suggesting that changes in stratification may also affect SST in this region of relatively shallow thermocline.

[16] In contrast, SST in the southwestern subtropics varies out of phase with SSTs in the southern Gulf of Guinea, giving rise to a northeast-southwest SST dipole (Figure 2b). This SST dipole occurs in conjunction with a weakening of the southeasterly trade winds and development of a more intense southern subtropical high pressure [Sterl and Hazeleger, 2003]. These changes in the wind field appear to be related to those reflected in the SLP-based St. Helena Island climatic index of Feistel et al. [2003] (Figure 2c).

[17] Interestingly, the east-west dipole in sea level (resulting from the westward propagation in the AEC) and the northeast-southwest dipole in SST vary together in time. However, the variation of SST in the western side of the basin is likely more the result of changes in the strength of the winds and thus wind-induced heat loss, as well as changes in wind-induced heat advection by the cold Malvinas current (as discussed by Wainer and Venegas [2002]) than a result of the presence of sea level anomalies.

\section{Summary and Discussion}

[18] This study is an extension of the altimeter-based study of Witter and Gordon [1999] to consider interannual variability of the South Atlantic by examination of the now 13 -year long record of satellite altimeter sea level data. By annually averaging the data we suppress the variability induced by intense eddies and find a succession of sea level anomalies with $10 \mathrm{~cm}$ amplitudes and five year timescales that propagate at a speed of $4 \mathrm{~cm} \mathrm{~s}^{-1}$ westward across the South Atlantic in the latitude band of the Aghulas Eddy Corridor $\left(35^{\circ} \mathrm{S}-25^{\circ} \mathrm{S}\right)$. We find that these westward propagating interannual anomalies are likely Rossby Waves produced by thermocline anomalies originating in the local and remote air-sea interactions of the equatorial zone. In the southeastern subtropics these sea level anomalies and the corresponding changes in stratification induce $0.5^{\circ} \mathrm{C} \mathrm{SST}$ anomalies that may be of importance for the climate of the South Atlantic sector [Robertson et al., 2003; Haarsma et al., 2003]. The cause of interannual variations of SST in the western South Atlantic is likely more complicated. Previous research has suggested that wind-induced thermodynamic fluxes as well as temperature advection may be prominent terms in the mixed layer heat budget in the west.

[19] The fate of the westward-propagating sea level anomalies after they enter the western South Atlantic is unclear based on the altimetry record. One possibility is that they propagate equatorward as waves trapped along the South American coast and shelf, thus closing the circle. We found evidence of such a scenario in the altimeter data for only the Atlantic Nino of 1999. The resulting sea level anomaly reached the western boundary in 2003 and transited the South America coast to the equator by 2004. However an observational assessment of the statistics of this method of exchange from the subtropics back to the tropics will require significantly longer sea level records.
[20] Acknowledgments. We gratefully acknowledge support from the NASA's Oceans Program and NOAA's Office of Global Programs. The altimeter products are produced by the CLS Space Oceanography Division with support from CNES. QuikSCAT wind is provided by the Seaflux data system at NASA/JPL through the courtesy of W. Timothy Liu and Wenqing Tang. The St. Helena climatic index is provided and updated by Rainer Feistel of Baltic Sea Research Institute, Germany.

\section{References}

Atlas, R., R. N. Hoffman, S. C. Bloom, J. C. Jusem, and J. Ardizzone (1996), A multiyear global surface wind velocity dataset using SSM/I wind observations, Bull. Am. Meteorol. Soc., 77, 869-882.

Campos, E. J. D., C. A. D. Lentini, J. L. Miller, and A. R. Piola (1999), Interannual variability of the sea surface temperature in the South Brazil Bight, Geophys. Res. Lett., 26, 2061-2064.

Carton, J. A., X. H. Cao, B. S. Giese, and A. M. daSilva (1996), Decadal and interannual SST variability in the tropical Atlantic Ocean, J. Phys. Oceanogr., 26, 1165-1175.

Colberg, F., C. J. C. Reason, and K. Rodgers (2004), South Atlantic response to El Niño-Southern Oscillation induced climate variability in an ocean general circulation model, J. Geophys. Res., 109, C12015, doi:10.1029/2004JC002301.

Ducet, N., P. Y. Le Traon, and G. Reverdin (2000), Global high-resolution mapping of ocean circulation from TOPEX/Poseidon and ERS-1 and -2, J. Geophys. Res., 105, 19,477-19,498.

Feistel, R., E. Hagen, and K. Grant (2003), Climatic changes in the subtropical southeast Atlantic: The St. Helena Island climatic index (19831999), Prog. Oceanogr., 59, 321-337.

Florenchie, P., J. R. E. Lutjeharms, C. J. C. Reason, S. Masson, and M. Rouault (2003), The source of Benguela Niños in the South Atlantic Ocean, Geophys. Res. Lett., 30(10), 1505, doi:10.1029/2003GL017172.

Garzoli, S. L., and A. L. Gordon (1996), Origins and variability of the Benguela Current, J. Geophys. Res., 101, 897-906.

Gordon, A. L., R. F. Weiss, W. M. Smethie Jr., and M. J. Warner (1992), Thermocline and intermediate water communication between the South Atlantic and Indian oceans, J. Geophys. Res., 97, 7223-7240.

Graf, J., C. Sasaki, C. Winn, W. T. Liu, W. Tsai, M. Freilich, and D. Long (1998), NASA Scatteromometer Experiment, Acta Astronaut., 43, 397-407.

Haarsma, R. J., E. J. D. Campos, and F. Molteni (2003), Atmospheric response to South Atlantic SST dipole, Geophys. Res. Lett., 30(16), 1864, doi:10.1029/2003GL017829.

Hirst, A. C., and S. Hastenrath (1983), Atmosphere ocean mechanisms of climate anomalies in the Angola tropical Atlantic sector, J. Phys. Oceanogr., 13, 1146-1157.

Killworth, P. D., D. B. Chelton, and R. A. DeSzoeke (1997), The speed of observed and theoretical long extratropical planetary waves, J. Phys. Oceanogr., 27, 1946-1966.

Matano, R. P., and E. J. Beier (2003), A kinematic analysis of the Indian/Atlantic interocean exchange, Deep Sea Res., Part II, 50, 229-249.

Peterson, R. G., and L. Stramma (1991), Upper level circulation in the South Atlantic Ocean, Prog. Oceanogr., 26, 1-73.

Reynolds, R. W., and T. M. Smith (1994), Improved global sea surface temperature analyses using optimum interpolation, J. Clim., 7, 929948 .

Robertson, A. W., J. D. Farrara, and C. R. Mechoso (2003), Simulations of the atmospheric response to South Atlantic sea surface temperature anomalies, J. Clim., 13, 2540-2551.

Schouten, M. W., R. P. Matano, and T. P. Strub (2005), A description of the seasonal cycle of the equatorial Atlantic from altimeter data, Deep Sea Res., Part I, 52, 477-493.

Servain, J., J. Picaut, and J. Merle (1982), Evidence of remote forcing in the rquatorial Atlantic Ocean, J. Phys. Oceanogr., 12, 457-463.

Sterl, A., and W. Hazeleger (2003), Coupled variability and air-sea interaction in the South Atlantic Ocean, Clim. Dyn., 21, 559-571.

Venegas, S. A., L. A. Mysak, and D. N. Straub (1997), Atmosphere-ocean coupled variability in the South Atlantic, J. Clim., 10, 2904-2920.

Wainer, I., and S. Venegas (2002), South Atlantic variability in the climate system model, J. Clim., 15, 1408-1420.

Witter, D. L., and A. L. Gordon (1999), Interannual variability of South Atlantic circulation from 4 years of TOPEX/Poseidon satellite altimeter observations, J. Geophys. Res., 104, 20,927-20,948.

J. A. Carton and S. A. Grodsky, Department of Atmospheric and Oceanic Science, University of Maryland, College Park, MD 20742, USA. (senya@atmos.umd.edu) 